\title{
ERRÂNCIA E NORMALIZAÇÃO SOCIAL: UM ESTUDO SOBRE ANDARILHOS DE ESTRADA
}

\author{
Eurípedes Costa do Nascimento \\ José Sterza Justo \\ Sonia Aparecida Moreira Françaף
}

\begin{abstract}
RESUMO. O nomadismo contemporâneo associado à migração, pobreza, desemprego e desfiliação social é uma característica marcante de nosso tempo e se expressa com maior radicalidade no fenômeno da errância, compreendida por uma perambulação a pé do indivíduo pelas rodovias, sem rumo certo e destino definido. O presente artigo tem por objetivo analisar a relação entre a errância e a normalização social, tendo como foco de análise o caso dos andarilhos de estrada.
\end{abstract}

Palavras-chave: Errância; normalização social; andarilhos de estrada.

\section{WANDERING AND SOCIAL NORMALIZATION: A STUDY ABOUT HIGHWAY WANDERERS}

\begin{abstract}
The contemporary nomadic life related to migration, poverty, unemployment and social disaffiliation is a common characteristic of our time and it can be seen radically in the wandering phenomenon understood as a displacement on foot of the individual through the highways without certain course and no definite destination. The present paper aims to analyze the relation between the wandering and the social normalization being the highway wanderers the main analysis focus.
\end{abstract}

Key words: Wandering; social normalization; highway wanderers.

\section{ERRANTES Y NORMALIZACIÓN SOCIAL: UN ESTUDIO SOBRE ANDARIEGOS DE CARRETERA}

RESUMEN. El nomadismo contemporáneo articulado con la migración, pobreza, desempleo y desafiliación social es una característica común de nuestro tiempo y puede ser percibido radicalmente en el fenómeno de los errantes, sujetos que son conocidos por caminaren a pie por las carreteras, sin rumbo cierto y destino definido. Ese artículo procura analizar la relación entre los errantes y la normalización social eligiendo como foco de análisis el caso de los andariegos de carretera.

Palabras clave: Errantes; normalización social; andariegos de carretera.

O ser humano vive atualmente uma condição de incertezas e movimentações sem precedentes, que o torna um transeunte de espaços geográficos, sociais e psicológicos. Deleuze (1992) destaca essa condição de movimentação na atualidade ao considerar uma notável modificação na constituição dos espaços sociais no início do século XVIII. Segundo o autor, os espaços fechados e as práticas de enclausuramento, típicas da sociedade disciplinar, estão sendo substituídos pelos espaços abertos e por práticas de controle modulares, ondulatórios e onipresentes, capazes de acompanhar os indivíduos em todos os seus movimentos e planos de existência.

Foucault $(1979,1984)$ destaca que essas práticas de controle têm por finalidade administrar a vida dos sujeitos na sociedade com vista a manter o equilíbrio e

* Doutorando em Psicologia e Sociedade pela Universidade Estadual Paulista-Unesp/Assis

\# Doutor em Psicologia Social. Docente nos cursos de Graduação e Pós-Graduação em Psicologia da Universidade Estadual Paulista-Unesp/Assis.

II Doutora em Psicologia Clínica. Docente no curso de Pós-Graduação em Psicologia da Universidade Estadual PaulistaUnesp/Assis. 
a ordem preestabelecida por meio da normalização social, compreendida por um conjunto de medidas que permite classificar, distribuir, hierarquizar, controlar, categorizar e comparar os sujeitos de acordo com as suas vicissitudes, de modo que as diferenças sociais como a inclusão, a exclusão e tantas outras formas de constituição do sujeito - sejam desconsideradas em suas particularidades, visando a homogeneização. Ewald (1993) acrescenta que o processo de normalização social é um mecanismo sutil de controle, resultante do entrecruzamento nos campos do saber e do poder que se exerce na invisibilidade do espaço social pela comparação das desigualdades e naturalização das diferenças.

Nesse contexto, a errância se apresenta como um fenômeno radical dessa normalização, pois, conjugada com a migração, desemprego, pobreza e desqualificação profissional, ela se caracteriza por uma movimentação a pé, contínua e inexorável do sujeito pelas rodovias do país, sem rumo certo, sem destino e objetivos definidos. A errância se caracteriza, ainda, pela solidão, desamparo, miséria extrema, e por uma ruptura do sujeito com os nichos de fixação social aos quais pertencia - como família, trabalho, casa, bairro, etc. (Justo, 2000; Nascimento, 2008).

Partindo dessas considerações, o presente artigo tem por objetivo analisar a relação entre a errância e a normalização social tendo como foco principal de análise o caso dos andarilhos de estrada, sujeitos que radicalizam a errância, vivendo exclusivamente pelos acostamentos das estradas, sem destino, isolados e distantes de qualquer contato com as redes de assistência social. Em geral, são sujeitos maltrapilhos e caminham a pé pelas principais malhas rodoviárias que cortam o país com um saco às costas, onde carregam todos os seus pertences (Nascimento, 2008).

Vale ressaltar que os andarilhos de estrada diferenciam-se dos trecheiros, que, embora perambulem a pé pelas rodovias, ainda mantêm contatos com as instituições sociais; dos mendigos, que habitam as cidades e nelas permanecem, geralmente, por longos anos; e dos itinerantes, que transitam ou migram de uma cidade a outra em busca de melhores oportunidades sem se deslocar a pé, mas por meio de passes de ônibus concedidos pela prefeitura municipal (Justo \& Nascimento, 2005, Nascimento, 2008). Não obstante, para que possamos compreender o fenômeno da errância e a radicalidade dos andarilhos de estrada, faz-se necessário verificar no plano histórico como se constituem a normalização social e o individualismo contemporâneo.

\section{NORMALIZAÇÃO SOCIAL E INDIVIDUALISMO CONTEMPORÂNEO}

O processo de normalização social a que nos referimos neste artigo será compreendido a partir das análises desenvolvidas por Michel Foucault (1979) sobre as ciências humanas e biológicas em seus estudos sobre a incidência do poder na vida do sujeito. Para Foucault, as ciências humanas e biológicas constituem práticas sociais que estruturam os regimes de enunciação e de visibilidade vinculados ao que ele define como biopoder, ou seja, tecnologias capazes de produzir procedimentos, saberes e estratégias de força nas relações sociais que sustentam o corpo como objeto de investigação do poder. Segundo Dreyfus e Rabinow (1995), a finalidade do biopoder é fabricar corpos passíveis de serem manipulados, investigados e disciplinados com a finalidade de torná-los dóceis e produtivos de acordo com os padrões socialmente aceitáveis pelas culturas em que se privilegia o individualismo como marca de autenticidade do eu e da excelência.

Conforme esses autores, o poder disciplinar compreendido como uma política de organização dos corpos que tem por função intensificar a utilidade e a produtividade dos indivíduos, fixar populações, examinar e organizar diferentes domínios da atividade humana - parece emergir com os modos de produção capitalista que exige e obriga o sujeito a se individualizar e a se automatizar constantemente em busca da desejável inclusão e aceitação social. Desse modo, o indivíduo ao ser manipulado pela tecnologia disciplinar, parece se alienar nas tentativas de soberania e governo de si e delegar a sua necessidade de autoconhecimento às tecnologias de exame e confissão oriundas das instituições cristãs.

Assim, a noção de indivíduo para Foucault (1985), parece estar associada a essas tecnologias de exame e confissão que combinam vigilância, sansão normalizadora e a hermenêutica de si em que o indivíduo é percebido como objeto a ser decifrado e, também, como sujeito que decifra. Dessa forma, por meio da tecnologia de exame o indivíduo é considerado em suas minúcias a partir de alguns regimes disciplinares tais como procedimentos, saberes, técnicas e descrições, associados ao controle, vigilância e confissão. Ou seja:

O indivíduo moderno - objetivado, analisado e fixado - é uma realização histórica. O poder não aplica seu saber, suas investigações, suas técnicas ao universal, mas ao indivíduo como objeto e efeito de um entrecruzamento do poder e do saber. $\mathrm{O}$ 
indivíduo é o produto de desenvolvimentos estratégicos complexos no campo do poder e de múltiplos desenvolvimentos nas ciências humanas. (Dreyfus \& Rabinow, 1995, p. 188).

Para esses autores, essas tecnologias de exame e confissão - o visto e o dito - parecem determinar o sujeito contemporâneo, pois, além das sansões normalizadoras que decretam o que ele pode e não pode fazer, a sexualidade surge como uma problemática a ser decifrada e isso irá incidir de maneira avassaladora sobre os seus processos identitários, na qual o indivíduo passa a ser objeto incessante da investigação científica. Isso acontece porque a sexualidade torna-se a razão de ser do sujeito e o lugar originário da verdade, ou seja, ela define o indivíduo e decifra seu modo de se relacionar no mundo, sendo suas raízes uma construção histórica do século XIX. Antes desse período, a noção de sexo era relativamente livre e indiferenciada do valor conotativo e substancial atribuído posteriormente.

A importância conferida à sexualidade possibilitou a intensificação das tecnologias de confissão e autoexame da consciência, proporcionando a expansão do biopoder, pois o sujeito, para se autoconhecer, necessita explicitar seus segredos mais íntimos e, para tanto, torna-se objeto a conhecer. Assim, “(...) a sexualidade é uma questão individual: ela diz respeito aos prazeres individuais ocultos, aos excessos perigosos para o corpo, às fantasias secretas; passou a ser considerada como a essência do ser humano individual e o núcleo da identidade pessoal" (Dreyfus \& Rabinow, 1995, p. 188).

Destarte, a noção de indivíduo/individualidade, para Foucault (1985), parece estar relacionada às tecnologias de exame e confissão que transformaram as relações do sujeito consigo mesmo e, consequentemente, com a natureza e os outros. Nesse sentido, o que parece interessar nessa trama subjetivante e ao mesmo tempo alienante é a hermenêutica de si por meio da sexualidade, pois somente ela proporcionará ao indivíduo a verdade sobre si mesmo ao decifrar as vicissitudes dos desejos mais íntimos do eu.

Desse modo, com o surgimento das diversas tecnologias do biopoder (disciplina, exame e confissão), as ações individuais dos sujeitos passam a ser ignoradas pelo Estado, que se ocupa somente com os interesses da coletividade, pois constitui uma nova forma política de poder que descentraliza suas ações, desconsidera as particularidades de cada indivíduo e responsabiliza o sujeito pelos seus próprios fracassos e tentativas de pertencimento social. Nesse sentido, o Estado se constitui como “(...) uma estrutura muito sofisticada na qual os indivíduos podem ser integrados sob uma única condição: que a esta individualidade se atribuísse uma nova forma, submetendo-a a um conjunto de modelos muito específicos" (Foucault, 1995, p. 237).

Essa nova forma de governo e gerenciamento dos corpos, peculiar ao Estado Moderno, parece estar relacionada com uma antiga tecnologia de poder originada nas instituições cristãs que Foucault (1995) define como poder pastoral. Segundo Foucault, a função do poder pastoral é cuidar e/ou se sacrificar pela salvação do rebanho, portanto, é uma forma de poder que “(...) não cuida apenas da comunidade como um todo, mas de cada indivíduo em particular, durante toda sua vida... está ligada à produção de verdade - a verdade do próprio indivíduo" (p. 237).

De acordo com Foucault (1995), essa produção de verdade seria uma das formas de objetificação do sujeito nas práticas sociais que surgiram das chamadas práticas divisórias, fracionando o indivíduo no seu próprio interior (corpo/mente), apartando-o dos outros (louco/sadio) e possibilitando, dessa forma, o controle dos indivíduos por meio dos dispositivos do biopoder, de modo que o sujeito, assim constituído, pode ser visto como um objeto analisável, categorizável e discriminável.
Neste processo de objetificação e categorização, os indivíduos recebem tanto uma identidade social quanto pessoal. De forma geral, "práticas divisórias" são modos de manipulação que combinam a mediação de uma ciência (ou pseudociência) e a prática de exclusão, geralmente num sentido espacial, mas sempre num sentido social... são técnicas de dominação e têm sido aplicadas principalmente em populações vagabundas, em classes trabalhadoras, naqueles definidos como marginais, etc. (Rabinow, 1999, p. 32-34).

Com efeito, o indivíduo, nesse modelo de categorização e objetificação social, passa a ser minuciosamente controlado e decifrado pelas sutilezas do poder e do saber, que, associadas ao Estado, comandam tanto os interesses individuais como os interesses coletivos, pois sua função é manter o equilíbrio e garantir o funcionamento da ordem preestabelecida. Trata-se, portanto, de uma forma de poder que individualiza e, ao mesmo tempo, totaliza o sujeito nas estruturas políticas através da tecnologia disciplinar, cujo objetivo principal é forjar um corpo dócil e produtivo que permita a distribuição, a 
organização e a supervisão dos indivíduos no espaço social.

(...) o interesse individual - como consciência de cada indivíduo constituinte da população - e o interesse geral - como interesse da população, quaisquer que sejam os interesses e as aspirações individuais daqueles que a compõem - constituem o alvo e o instrumento fundamental do governo da população (Foucault, 1979, p. 289).

Destarte, a tecnologia disciplinar parece possibilitar o controle dos indivíduos e regulamentar sua operacionalidade por meio da normalização social que trabalha na lógica da individuação, fazendo o sujeito voltar-se sobre si mesmo a fim de se reconhecer e se distinguir dos demais. Segundo Foucault (1985), o conceito de normalização social pode ser compreendido como um sistema de intervalos mensuráveis que tem por objetivos qualificar, classificar, avaliar e hierarquizar o indivíduo para que possa ser controlado pelos dispositivos de segurança como meio de garantir sua efetividade e estabilidade social. Rabinow (1999) esclarece que esse processo de normalização social serve, também, para controlar e isolar as anomalias no corpo social mediante procedimentos corretivos ou até mesmo terapêuticos, pois, “(...) o sistema de normalização está em oposição a um sistema legal ou de poder pessoal; não há pivôs fixos a partir dos quais se fazem julgamentos e se impõem vontades" (p. 44).

Desse modo, as relações estabelecidas pelo sujeito na sociedade parecem estar determinadas pela ação normalizadora, ou seja, por relações de poder e saber que se enraízam no conjunto da rede social e promulgam sentenças ou regimes de enunciação entre verdadeiro/falso, além de operacionalizar as formas de governabilidade do Estado. Assim, os exercícios de poder e saber engendrados nas redes sociais sancionam as normas a que o sujeito deve se submeter e se adequar se quiser permanecer visível ou pertencer ao ideal de sociabilidade construído pelos modos de operar das práticas sociais.

Com efeito, a eficácia da normalização social parece determinar a comparação e a individualização, possibilitando, ainda, às disciplinas “(...) neutralizar perigos, fixar populações errantes e aumentar a utilidade dos indivíduos... tornando possíveis as comparações, permitindo à sociedade ou ao grupo comunicarem-se consigo próprio" (França, 1997, p. 208). Nesse sentido, a efetividade da norma parece cumprir sua finalidade fundamental, que é estabelecer certo equilíbrio nos campos de força das redes sociais.
O reflexo dessas ações no plano sociopsicológico contemporâneo é a organização de uma sociedade do espetáculo (Debord, 1991), em que a regra é a celebração do eu na teatralidade social porque é o próprio sujeito quem precisa criar sua marca registrada e se diferenciar dos demais por meio do culto da performance (Ehrenberg, 1991). Segundo esses autores, o padrão socialmente aceitável de qualidade do eu está relacionado com as cláusulas preestabelecidas pela sociedade, segundo as quais o que importa é a performance ou a realização pessoal do sujeito mediante um autêntico processo de singularização em que as ostentações pessoais ou as impressões de sucesso parecem determinar o grau de diferenciação e o status de cada um na hierarquia social.

Neste sentido, o sucesso e a realização pessoal parecem estar condicionados pelas regras comandadas pela exterioridade em que o sujeito do desejo se transforma em sujeito do objeto, ou seja, a referência subjetiva do indivíduo pautada na ordem da interioridade (desejo) é invertida nessa nova dimensão da individualidade narcisista que celebra as "qualidades" externas (aparência) como única condição de distinção e pertencimento social (Birman, 2000). Conforme o autor, os modos de referência para a subjetividade e o bem-estar contemporâneo estão pautados agora na noção de concorrência e competitividade a partir de uma demanda comandada pela exterioridade.

Desse modo, a noção de interioridade que no início do século XX, com a psicanálise freudiana e o marxismo, era centrada na ordem do desejo e do ideário de revolução, perdeu sua raison d'être na contemporaneidade que só reconhece o sujeito pela sua exterioridade. Em outras palavras, o sujeito do desejo acreditava que poderia “(...) transformar a si mesmo e ao mundo de maneira a poder reinventar a si mesmo e a ordem social... Foi justamente essa crença que se perdeu na pós-modernidade" (Birman, 2000, p. 82-84). Conforme podemos observar nas palavras do autor, era o desejo que mediava as demandas da subjetividade e determinava a participação do sujeito na construção histórica da sociedade. Assim,

(...) a modernidade foi construída em torno do ideário da revolução, que materializava, como metáfora, a crença transformadora do sujeito coletivo... até que a atualidade pósmoderna lançou uma pá de cal em tal pretensão... na medida em que não seria mais reconhecida como produtora de historicidade. (Birman, 2000, p. 82-83). 
Dessa maneira, a elaboração da subjetividade passou da ordem do desejo (interioridade) para uma modalidade de pensamento pautada na exaltação do eu e da excelência (exterioridade) ou no culto da performance do "meu" desejo. Nesse sentido, o indivíduo contemporâneo parece se constituir, fundamentalmente, pelo autocentramento de si a partir de uma mise-en-scène exibicionista, pois, o que caracteriza esta performance narcísica do eu é exatamente o excesso de exterioridade. Assim a interioridade do desejo parece perder sua função nessa nova constituição do sujeito que é reconhecível e admirável a partir da exterioridade comandada pelo poder social que determina como o indivíduo deve se apresentar para ser aplaudido, reconhecido ou ignorado na sociedade do espetáculo (Debord, 1991).

\begin{abstract}
O espetáculo não é um conjunto de imagens, mas uma relação social entre pessoas, mediada por imagens... é a afirmação da aparência e a afirmação de toda vida humana - isto é, social - como simples aparência. Mas a crítica que atinge a verdade do espetáculo o descobre como a negação visível da vida; como a negação da vida que se tornou visível. (Debord, 1991, pp. 14-16grifado no original).
\end{abstract}

Deste modo, é a performance ou a encenação narcisista do eu que parece interessar à sociedade do espetáculo em que o jogo de imagens e o marketing pessoal do indivíduo precisam ganhar espaço e contorno na teatralidade social e sobressair com sucesso em quaisquer circunstâncias. $\mathrm{O}$ indivíduo assume, nesse caso, um caráter eminentemente maquiado no sentido da busca pela grandeza pela admiração dos outros em que os afetos e as relações de intimidade são colocados em segundo plano, sem muita importância. O sujeito contemporâneo pode, então, ser compreendido como um sujeito da exterioridade por excelência, inserido numa cultura do narcisismo, na qual as aparências e as imagens de sucesso valem mais que os atributos éticos e morais (Lasch, 1983; Debord, 1991; Ehrenberg, 1991).

(...) o sucesso aparece como um fim em si mesmo... as aparências - as "imagens de vitória" - contam mais que o desempenho, a atribuição mais do que a realização... Nada faz mais sucesso do que a aparência de sucesso... Hoje em dia, os homens buscam o tipo de aprovação que aplaude não suas ações, mas seus atributos pessoais... Desejam não a fama, mas o fascínio e a excitação da celebridade (Lasch, 1983, p. 86-87).
Assim, as relações dos indivíduos na sociedade contemporânea parecem se estabelecer a partir de uma encenação de si na qual a ostentação material e a imagem de sucesso possibilitam o reconhecimento e a distinção da individualidade na sociedade do espetáculo. Nesse contexto, a marginalidade, a pobreza extrema, a miséria absoluta e tantas outras formas de existência interpretadas como "exclusões" parecem se efetivar pela constatação visível e cabal da legitimidade da ação normalizadora, pois são essas mesmas "exclusões" que garantem a manutenção e o equilíbrio das diferenças, permitindo que as desigualdades sociais sejam banalizadas e até mesmo naturalizadas na cultura da excelência. Nesse caso, o fenômeno da errância perpetrado pelos andarilhos de estrada pode ser tomado como um dos exemplos mais radicais e contrastantes de uma sociedade altamente sofisticada, mas órfã de sentidos humanos.

\section{NORMALIZAÇÃO SOCIAL E ERRÂNCIA}

Se considerarmos o individualismo atual como o resultado de uma organização narcisista em que o sujeito precisa criar sua visibilidade no cenário social e diferenciar-se dos demais para se manter no topo da performance, a errância aparece nesse contexto como um contraste substancial da atualidade por apresentar um sujeito despossuído de bens e quaisquer garantias de inserção social. A errância, aliás, representa aqui a constatação inequívoca da efetividade da normalização social, pois, no processo normativo o que parece ocorrer é uma equiparação entre as diferenças e esse procedimento é o que possibilita a sustentabilidade no regime de visibilidade e de enunciação entre sujeito e objeto, garantindo sua conformidade.

Vale ressaltar que, nesse caso, a errância representa a inversão do ideal de sustentabilidade do sujeito no espaço social, pois, ela se situa na margem oposta da cultura do narcisismo sem, no entanto, diferenciar-se dela no que se refere ao individualismo. Tanto na cultura do narcisismo como na cultura do espetáculo é a individualidade que se destaca como condição de ser do sujeito na atualidade e possibilita suas diferenciações. Nesse sentido, podemos conjeturar que há, no espaço social contemporâneo, dois tipos contrastantes de enunciação do sujeito: um relacionado ao narcisismo positivo, caracterizado pela excelência da imagem e pelo reconhecimento de sucesso e status social (tais como os empresários, as celebridades, os atores de cinema, telenovela, etc.) e o outro associado a um narcisismo negativo, constituído pela decadência da imagem e pelos fracassos do 
indivíduo no espaço social, como é o caso dos andarilhos de estrada, dos mendigos, dos sem-teto, dos sem-terra, etc. (Lasch, 1983; Debord, 1991; Castel, 1994, 1998).

Seja como for, em ambos os modos de enunciação do sujeito o que parece se destacar é o caráter inequívoco da individualidade por excelência. No caso do narcisismo positivo, trata-se de uma individualidade espetacular marcada pela celebração de si mesmo, ou seja, é o eu do indivíduo quem sobressai e se destaca no espaço social. No caso do narcisismo negativo, trata-se de uma individualidade pusilânime em que o eu do sujeito é considerado um fracassado nas tentativas de celebração social e deslocado para a marginalidade; ou seja, enquanto o individualismo positivo procura se destacar na sociedade do espetáculo e garantir sua sociabilidade, o individualismo negativo luta para manter sua própria subsistência, num narcisismo às avessas e miseravelmente atormentador (Castel, 1994, 1998).

(...) nessa sociedade existem formas de individualização que poderiam ser classificadas de individualismo negativo, que são obtidas por subtração em relação ao encastramento em coletivos... O vagabundo representa-lhe o paradigma... Individualismo negativo porque se declina em termos de falta - falta de consideração, falta de seguridade, falta de bens garantidos e de vínculos estáveis. (Castel, 1998, p. 596-98 grifado no original).

Contudo, não devemos compreender o fenômeno da errância na atualidade apenas como um problema de "exclusão" social que diz respeito à natureza de um corpo. No caso de indivíduos que se situam em graus diferenciados, aquém ou além do ideal de sociabilidade (como os andarilhos de estrada e os miseráveis de toda ordem), devemos compreendê-los, antes, como efeito do trabalho da normalização social. Castel (1998) é quem nos dá a dica sobre essa conceitualização, ao apontar que o termo "exclusão" não deve ser empregado em estudos de natureza social porque não há, segundo ele, ninguém desligado do sistema que opera, controla e distribui os indivíduos conforme suas necessidades.

(...) a exclusão não é uma ausência de relação social, mas um conjunto de relações sociais particulares da sociedade tomada como um todo. Não há ninguém fora da sociedade, mas um conjunto de posições cujas relações com o centro são mais ou menos distendidas... É do centro que parte a onda de choque que atravessa a estrutura social (...) Os "excluídos"(...) encontram-se desfiliados, e esta qualificação lhes convém melhor do que a de excluídos: foram desligados, mas continuam dependendo do centro que, talvez, nunca foi tão onipresente para o conjunto da sociedade. (Castel, 1998, p. 568-9 - grifado no original)

Conforme podemos apreender no enunciado desse autor, a desfiliação, em substituição ao termo "exclusão", pode ser compreendida aqui como um sistema de categorização social que inclui desde o business man bem-sucedido até o homeless man das classes marginais, pois a diferenciação entre ambos é apenas conjuntural ou distendida. Assim, a ação normalizadora parece categorizar e classificar o sujeito de acordo com o grau de seu pertencimento e banaliza as diferenças como algo natural e necessário para o equilíbrio e a manutenção da ordem preestabelecida.

Nesse sentido, a categorização e a distribuição de determinados indivíduos é o que garante a manutenção da norma e das formas que estabelecem as diferenças, possibilitando a sustentabilidade e o exercício de poder e saber que homogeneíza o espaço social. Desse modo, as práticas sociais normativas são formas historicamente construídas “(...) que vieram dar contorno às forças, às sansões que são colocadas em jogo no encontro dos corpos, pois o poder se exercita no mesmo instante em que inventa matérias para suas operações" (França, 1997; p. 210).

Portanto, o que se considera "exclusão", lato sensu, nada mais é do que apropriações, campos de visibilidade dos efeitos desses encontros dos corpos. Sob a sustentabilidade da norma é possível compreender, então, a desfiliação, as desigualdades no espaço social, os contornos meticulosos do poder e a produção de verdade que rege os acontecimentos nas esferas ética e política. Sendo assim, a marginalização, a pauperização extrema e a radicalidade da errância constituem um corpus operandi que equilibra os modos de agir da norma, racionalizando as diferenças pela comparação.

O efeito da sansão normalizadora é complexo. Ele parte da premissa de que todos os indivíduos são formalmente iguais. Isto conduz a uma homogeneidade inicial a partir da qual se estabelece a norma de conformidade. Porém, uma vez posto este aparelho em movimento, há uma diferenciação e uma individuação cada vez mais sutis, que separam e organizam os indivíduos objetivamente (Dreyfus \& Rabinow, 1995, p. 175). 
Nesse sentido, nem mesmo a errância radical perpetrada pelos andarilhos de estrada escapa aos processos sutis da normalização social que procura ordenar, controlar e direcionar tais movimentações caóticas no espaço social contemporâneo. Além de confinados aos corredores de circulação formados pelas rodovias, os andarilhos se sujeitam, ainda, aos direcionamentos de suas rotas impostas pelas instituições municipais de assistência encarregadas de fazer escoar a movimentação da errância, principalmente as instituições localizadas nas cidades do Interior Paulista que muitas vezes procuram impedir a entrada desses indivíduos no perímetro urbano no sentido de manter o equilíbrio e a estabilidade local (Nascimento, 2008).

Nossas pesquisas em algumas dessas instituições assistenciais têm indicado que os errantes, ao adentrarem nessas cidades, são imediatamente retirados de circulação e conduzidos para essas instituições que os redirecionam para outras localidades distantes por meio de ônibus intermunicipais, interestaduais ou mesmo a pé quando se esgotam todos os recursos disponíveis (Justo \& Nascimento, 2005; Nascimento, 2008). Nessas instituições municipais que visitamos, foi possível observar tais constatações quando os funcionários investigavam a procedência e o destino dos andarilhos, bem como avaliavam seu estado de "periculosidade" para o município. Seja como for, a maioria desses sujeitos é lançada nas rodovias rumo a outras localidades distantes do município, fortalecendo, assim, o caráter de operacionalidade da norma e a manutenção da errância na invisibilidade do poder, possibilitando, ainda, a homogeneização das diferenças por meio de mecanismos sutis de controle e vigilância social.

Vale ressaltar que essas medidas de contenção e controle podem ser perfeitamente comparadas com a política de higienização social que caracterizou as práticas médicas no início do século XX, na qual havia um meticuloso controle e vigilância das famílias no sentido de manter a ordem, a assepsia e a disciplina (Costa, 1989). No caso da errância, o que parece ocorrer é a impossibilidade de o sujeito circular livremente pelas ruas da cidade que precisam ficar "limpas" e "esterilizadas" da heterogeneidade. Algumas cidades, para se proteger contra a "invasão" dos miseráveis de toda a sorte, adotam certos procedimentos políticos (provenientes do bipoder) que visam conter a circulação e a movimentação dessas diferenças no espaço social, no sentido de "higienizar" as ruas e evitar o "contágio" para manter a suposta homogeneidade e o equilíbrio da ordem preestabelecida pela normalização social.

Neste sentido, até mesmo os mendigos, que se caracterizam por sua permanência fixa nas ruas das cidades, estão sendo retirados de circulação por algumas instituições assistenciais e colocados em marcha para outras localidades. Isso nos permite constatar que parece não haver mais lugar para os miseráveis no espaço das cidades, pois, eles representam a diferença que precisa ser contida e evitada para a manutenção da estabilidade e do controle social. Assim, impossibilitados de circular pelas cidades, esses sujeitos são distribuídos pelas rodovias, o único lugar passível de circulação e controle das diferenças, numa perambulação interminável e sob o comando e a vigilância da ação normalizadora.

Assim, o fenômeno da errância parece ilustrar bem as vicissitudes e os paradoxos da contemporaneidade na qual os andarilhos de estrada representam a caricatura do homem por si só, impulsionado a abandonar seu lugar de origem para viver a esmo na estrada, sob o signo da individualidade negativa, do movimento sem rumo certo e sem fixação social. Circunscritos nas malhas rodoviárias, fazem da perambulação constante sua condição exclusiva de existência, permitindo, assim, a garantia de ação e sustentabilidade da normalização social que organiza, controla e distribui as multiplicidades.

A perambulação pelo asfalto é um fato incontestável na vida desses sujeitos, pois todos estão submetidos à imposição radical de movimentação pelas rodovias, tendo que se submeter passivamente aos corredores da incerteza e da lassidão. A rodovia pode até ser entendida, nesse caso, como a própria extensão de sua casa perene, sua morada móvel e sua fonte rudimentar de subsistência. Assim, a normalização social passa a incidir, também e sobretudo, sobre a movimentação e a perambulação do sujeito, criando corredores e ritmos de circulação mais do que pontos estáveis de estacionamento e ancoragem, sendo essas condições uma das características marcantes que assolam o mundo contemporâneo.

\section{CONSIDERAÇÕES FINAIS}

A normalização social pode ser considerada como um dos aspectos sutis da sociedade contemporânea, na qual o poder e o saber categorizam o sujeito pela individualidade e o subjuga em conformidade com os mecanismos de exploração e dominação nas redes de sociabilidade. As relações do sujeito nesse contexto podem ser tomadas a partir de uma relação pautada numa mise-en-scène individualista e exibicionista, na qual a existência do eu é determinada pela alta performance na cultura do narcisismo que decide ou delimita o ideal de pertencimento social de cada indivíduo de acordo com o grau de sua espetacularização.

A errância dos andarilhos de estrada se configura nesse território como um fenômeno radical do individualismo negativo em que o sujeito é posto em movimento e transitoriedade para possibilitar o controle e 
a manutenção do equilíbrio das desigualdades sociais comandadas pela sansão normalizadora. A errância representa, também, o paradigma contemporâneo em que o sujeito é individualizado a tal ponto que este modo de existência radical é potencializado e legitimado pelo corpus social como uma condição sine qua non dos mecanismos de produção, distribuição e categorização que visa manter a ordem, a estabilidade e a dispersão dos indivíduos. Situada especificamente nessa zona de instabilidade e turbulência, a errância representa claramente a condição do homem atual como um indivíduo permeado pela exterioridade, controlado, decifrado, sem autonomia e sem domínio de sua própria individualidade, principalmente quando está aquém do ideal de pertencimento social.

Dessa forma, as ofertas de subjetivação orientadas para a flexibilidade de sujeição do indivíduo, a fragmentação do pensamento, a instabilidade, a competitividade e o consumo desenfreado parecem incidir sobre os sentidos existenciais do homem, levandoo a uma crise de si mesmo ante uma realidade dispersiva, insegura e repleta de incertezas. Nesse cenário socialmente plasticizado pela individualidade, cabe-nos perguntar o que se pode fazer para promover uma transformação ético-estética e política nesse sujeito, centrado em si mesmo e controlado invisivelmente pelo biopoder.

Se ainda não temos uma resposta viável e segura para esse dilema contemporâneo, talvez seja o tempo de pensarmos em “(...) promover novas formas de subjetividade através da recusa deste tipo de individualidade que nos foi imposto há vários séculos" (Foucault, 1995, p. 239); ou seja, talvez a nossa grande tarefa hoje seja a elaboração de um outro discurso, capaz de amenizar a competitividade e o individualismo e de atenuar a confusão que permeia o mundo dos homens para torná-lo mais crível e menos entediante na construção de uma nova história.

\section{REFERÊNCIAS}

Birman, J. (2000). O mal-estar na atualidade. $2^{\text {a }}$ edição. Rio de Janeiro: Civilização Brasileira.

Castel, R. (1994). Da indigência à exclusão, a desfiliação. Em A. Lancetti (Org.). Saúde loucura 4. (pp. 21-48). São Paulo: Hucitec.

Castel, R. (1998). As metamorfoses da questão social. (I. D. Poleti, Trad.). Petrópolis, R. J.: Vozes. (Original publicado em 1995).
Costa, J. F. (1989). Ordem médica, norma familiar. $3^{\text {a }}$ edição. Rio de Janeiro: Graal.

Debord, G. (1991). A sociedade do espetáculo. Lisboa: Mobilis in Móbile.

Deleuze, G. (1992). Conversações. (P. P. Pelbart, Trad.). São Paulo: Editora 34. (Original publicado em 1990).

Dreyfus, H. L. \& Rabinow, P. (1995). Michel Foucault, uma trajetória filosófica: para além do estruturalismo e da hermenêutica. (V. P. Carrero, Trad.). Rio de Janeiro: Forense Universitária. (Original publicado em 1984).

Ehrenberg, A. (1991). Le culte de la performance. Paris: Calman-Lèvy.

Ewald, F. (1993). Foucault, a norma e o direito. Lisboa: Vega Editora.

Foulcault, M. (1984). Vigiar e punir (L. M. P. Vassalo, Trad.). Petrópolis: Vozes. (Original publicado em 1975).

Foucault, M. (1979). Microfísica do poder. (R. Machado, Trad.). Rio de Janeiro: Graal. (Original publicado em 1975).

Foucault, M. (1985). História da sexualidade I: A vontade de saber. (M. T. C. Albuquerque \& J. A. Albuquerque, Trads.). Rio de Janeiro: Graal. (Original publicado em 1976).

Foucault, M. (1995). O sujeito e o poder. Em H. L. Dreyfus \& P. Rabinow (Orgs.). Michel Foucault, uma trajetória filosófica: para além do estruturalismo e da hermenêutica. (pp. 231-49). Rio de Janeiro: Forense Universitária.

França, S. A. M. (1997). Diferença e preconceito: a efetividade da norma. Em J. G. Aquino (Org.). Diferença $e$ preconceito: alternativas teóricas e práticas. (pp. 203-14). São Paulo: Summus.

Justo, J. S. (2000). Saúde mental em trânsito: loucura e a condição de itinerância na sociedade contemporânea. Em M. L. Boarini (Org.). Desafios na atenção à saúde mental. (pp. 09-29). Maringá, PR: Eduem.

Justo, J. S. \& Nascimento, E. C. (2005). Errância e delírio em andarilhos de estrada. Psicologia: Reflexão e Crítica, 18 (2), pp. 177-87.

Lasch, C. (1983). A cultura do narcisismo. (E. Pavaneli, Trad.). Rio de Janeiro: Imago. (Original publicado em 1979).

Nascimento, E. C. (2008). Nomadismos contemporâneos: um estudo sobre errantes trecheiros. São Paulo: Editora Unesp.

Rabinow, P. (1999). Antropologia da razão. (J. G. Biehl, Trad.). Rio de Janeiro: Relume Dumará. (Original publicado em 1996).

Recebido em 23/04/2008 Aceito em 16/10/2008

Endereço para correspondência : Eurípedes Costa do Nascimento. Travessa Itaú, 02, Centro, CEP 37900-144, Passos-MG, Brasil.E-mail: nascimentoec@gmail.com 